\title{
Serum Protein N-Glycans in Colostrum and Mature Milk of Chinese Mothers
}

\author{
Mohèb Elwakiel, Edwin J. Bakx, Ignatius M. Szeto, Yitong Li, Kasper A. Hettinga, and Henk A. Schols* \\ Cite This: J. Agric. Food Chem. 2020, 68, 6873-6883 \\ Read Online
}

ABSTRACT: To study the Chinese human milk N-glycome over lactation, N-glycans were released and separated from serum proteins, purified by solid-phase extraction, and analyzed by matrix-assisted laser desorption ionization time-of-flight mass spectrometry (MALDI-TOF-MS). In total, 66 different putative N-glycans were found in the colostrum (week 1) and mature milk (week 4) of seven Chinese mothers. A clear difference was observed between milk of five secretor and two nonsecretor mothers, based on the type and relative amounts of the individual N-glycans. The relative levels of the total neutral nonfucosylated and the fucosylated N-glycans in milk of five secretor mothers increased and decreased over lactation, respectively. This pattern could not be observed for the milk from the two nonsecretor mothers. Overall, this was the first study that provided detailed information on individual $\mathrm{N}$-glycans in milk among mothers and over time as well as that fucosylation of N-glycans in milk was associated with the mother's secretor status.

KEYWORDS: glycoproteins, oligosaccharides, glycosylation, intestinal mucosal barrier

\section{INTRODUCTION}

Human milk is the best nutrition for infants during the first 6 months of life ${ }^{1}$ and stimulates the maturation of the infant's intestinal immune system. ${ }^{2}$ Human milk contains many biofunctional components, such as proteins and human milk oligosaccharides (HMOs). ${ }^{3}$ HMOs represent complex lactosebased glycans synthesized in the mammary gland during lactation, which reach the colon intact, and are able to stimulate the development of the bifidogenic flora. ${ }^{4,5}$ Human milk proteins among others play a pivotal role in protecting the infant's gut mucosa against pathogens. ${ }^{6}$ It has been reported that $70 \%$ of the human milk proteins in number are glycosylated. ${ }^{7}$ These protein-bound glycans among others might affect the folding and stability of proteins and modulate neonatal immunity by altering host epithelial and immune cell responses in the infant's gut. ${ }^{9-10}$

Caseins are divided into three main types $\left(\alpha_{\mathrm{S} 1}, \beta\right.$-, and $\kappa$ casein) and are a valuable source of amino acids, phosphate, and calcium, used for the growth of the neonate. ${ }^{11}$ The proteins $\alpha_{\mathrm{S}^{-}}$and $\beta$-casein in human milk do not have any glycosylated amino acid residues, while $\kappa$-casein has multiple $O$-glycosylation sites at various threonine residues. ${ }^{12}$ Serum proteins such as lactoferrin, immunoglobulins, serum albumin, and $\alpha$-lactalbumin form the main portion of the glycoproteins present in human milk and mainly contain $\mathrm{N}$-glycans. ${ }^{12}$ These glycans are attached to the amide nitrogen of an asparagine residue of the protein. ${ }^{13-16}$ There are also serum proteins that contain only $\mathrm{O}$-glycans (e.g., osteopontin) or contain both $\mathrm{O}$ glycans and N-glycans (e.g., bile salt-activated lipase). Osteopontin, lactoferrin, and immunoglobulins have direct bactericidal properties. ${ }^{12}$ In addition, many other glycosylated serum proteins can be found in human milk having a reported immune activity. ${ }^{12}$
$\mathrm{N}$-glycans can be assembled with four types of neutral monosaccharides: fucose (Fuc), galactose (Gal), mannose (Man), $N$-acetylglucosamine (GlcNAc), $N$-acetylgalactosamine (GalNAc). N-glycans can also contain the sialic acidic structure $N$-acetylneuraminic acid (NeuAc). ${ }^{14-19}$ All identified $\mathrm{N}$-glycans in human milk have a pentasaccharide as the common core, consisting of three Man and two GlcNAc residues. ${ }^{14-16} \mathrm{~N}$-glycans can be classified into three types, namely, high-mannose, complex, and hybrid N-glycans. ${ }^{20-23}$ High-mannose $\mathrm{N}$-glycans typically contain between two and six Man residues attached to the pentasaccharide core, whereas complex $\mathrm{N}$-glycans can be elongated at the mannose residues by GlcNAc residues, which are often further decorated by Gal and GalNAc residues. ${ }^{20-23}$ Hybrid N-glycans are composed of a pentasaccharide core, with one branch of mannose residues and another branch with one or two GlcNAc residues. ${ }^{20-23}$

Complex and hybrid N-glycans have a large variety of structures, and fucosylation might affect their conformation and functional properties. ${ }^{19}$ To date, 13 different fucosyltransferases (FUTs) have been detected in the human genome. $^{24}$ The FUT8 gene encodes for the $\alpha 1,6$-fucosyltransferase that transfers a Fuc residue to the innermost GlcNAc unit of N-glycan chains. ${ }^{24,25}$ Fucosylation of N-glycans also might partially depend on the FUT2 and FUT3 genes, ${ }^{24,25}$ which determine the mother's secretor ( $\mathrm{Se}$ ) and Lewis (Le) status. The FUT2 Se gene determines the presence of $\alpha 1,2-$

Received: April 6, 2020

Revised: $\quad$ May 31, 2020

Accepted: June 4, 2020

Published: June 4, 2020

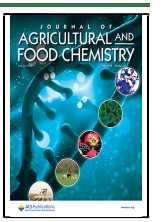


Table 1. Putative N-Glycans Identified in Colostrum (Week 1) and Mature Milk (Week 4) of Seven Chinese Mothers, Including Sugar Mass, Building Blocks, and Using Two Classification Systems

\begin{tabular}{|c|c|c|c|c|c|c|c|}
\hline \multirow[b]{2}{*}{ no. } & \multirow[b]{2}{*}{ mass } & \multicolumn{4}{|c|}{ composition } & \multicolumn{2}{|c|}{ classification: type } \\
\hline & & Hex & HexNAc & $\overline{\text { Fuc }}$ & $\overline{\text { NeuAc }}$ & $\overline{\mathrm{I}^{a}}$ & $\mathrm{II}^{b}$ \\
\hline N1 & $1056.4^{15}$ & 3 & 2 & 1 & 0 & other & $\mathrm{NF}$ \\
\hline $\mathrm{N} 2$ & $1072.3^{15}$ & 4 & 2 & 0 & 0 & other & $\mathrm{N}$ \\
\hline N3 & $1113.3^{16}$ & 3 & 3 & 0 & 0 & other & $\mathrm{N}$ \\
\hline N4 & 1202.4 & 3 & 2 & 2 & 0 & other & NF \\
\hline N5 & $1218.4^{15}$ & 4 & 2 & 1 & 0 & other & NF \\
\hline N6 & $1234.3^{14-16}$ & 5 & 2 & 0 & 0 & $\begin{array}{l}\text { high } \\
\text { mannose }\end{array}$ & $\mathrm{N}$ \\
\hline N7 & $1259.3^{16}$ & 3 & 3 & 1 & 0 & hybrid & $\mathrm{NF}$ \\
\hline N8 & $1275.4^{14,16}$ & 4 & 3 & 0 & 0 & hybrid & $\mathrm{N}$ \\
\hline N9 & $1316.3^{16}$ & 3 & 4 & 0 & 0 & complex & $\mathrm{N}$ \\
\hline N10 & 1380.6 & 5 & 2 & 1 & 0 & other & NF \\
\hline N11 & $1396.3^{14-16}$ & 6 & 2 & 0 & 0 & $\begin{array}{l}\text { high } \\
\text { mannose }\end{array}$ & $\mathrm{N}$ \\
\hline $\mathrm{N} 12$ & $1421.4^{14,16}$ & 4 & 3 & 1 & 0 & hybrid & $\mathrm{NF}$ \\
\hline N13 & $1437.4^{15}$ & 5 & 3 & 0 & 0 & hybrid & $\mathrm{N}$ \\
\hline $\mathrm{N} 14$ & $1462.5^{14}$ & 3 & 4 & 1 & 0 & complex & $\mathrm{NF}$ \\
\hline N15 & $1478.4^{14,15}$ & 4 & 4 & 0 & 0 & complex & $\mathrm{N}$ \\
\hline N16 & $1519.4^{14,16}$ & 3 & 5 & 0 & 0 & complex & $\mathrm{N}$ \\
\hline N17 & 1542.4 & 6 & 2 & 1 & 0 & other & NF \\
\hline N18 & $1558.4^{14-16}$ & 7 & 2 & 0 & 0 & $\begin{array}{l}\text { high } \\
\text { mannose }\end{array}$ & $\mathrm{N}$ \\
\hline N19 & $1566.9^{14,16}$ & 4 & 3 & 0 & 1 & hybrid & A \\
\hline $\mathrm{N} 20$ & $1583.4^{15}$ & 5 & 3 & 1 & 0 & hybrid & NF \\
\hline $\mathrm{N} 21$ & $1599.5^{14}$ & 6 & 3 & 0 & 0 & hybrid & $\mathrm{N}$ \\
\hline $\mathrm{N} 22$ & 1607.3 & 3 & 4 & 0 & 1 & hybrid & A \\
\hline $\mathrm{N} 23$ & $1624.5^{14,15}$ & 4 & 4 & 1 & 0 & complex & NF \\
\hline $\mathrm{N} 24$ & $1640.4^{14,15}$ & 5 & 4 & 0 & 0 & complex & $\mathrm{N}$ \\
\hline $\mathrm{N} 25$ & $1665.5^{14,16}$ & 3 & 5 & 1 & 0 & complex & $\mathrm{NF}$ \\
\hline $\mathrm{N} 26$ & $1681.5^{14}$ & 4 & 5 & 0 & 0 & complex & $\mathrm{N}$ \\
\hline $\mathrm{N} 27$ & $1720.4^{14-16}$ & 8 & 2 & 0 & 0 & $\begin{array}{l}\text { high } \\
\text { mannose }\end{array}$ & $\mathrm{N}$ \\
\hline $\mathrm{N} 28$ & 1722.5 & 3 & 6 & 0 & 0 & complex & $\mathrm{N}$ \\
\hline $\mathrm{N} 29$ & $1728.1^{15}$ & 5 & 3 & 0 & 1 & hybrid & A \\
\hline N30 & $1729.0^{15}$ & 5 & 3 & 2 & 0 & hybrid & NF \\
\hline N31 & $1769.5^{14}$ & 4 & 4 & 0 & 1 & complex & A \\
\hline N32 & $1770.8^{14}$ & 4 & 4 & 2 & 0 & complex & $\mathrm{NF}$ \\
\hline N33 & $1786.5^{14-16}$ & 5 & 4 & 1 & 0 & complex & $\mathrm{NF}$ \\
\hline N34 & 1802.5 & 6 & 4 & 0 & 0 & complex & $\mathrm{N}$ \\
\hline
\end{tabular}

linked fucosylated glycans. ${ }^{26}$ The addition of Fuc residues by an $\alpha 1,3 / 4$-linkage on the antennae of GlcNAc might be regulated by FUT3 or other $\alpha 1,3$-genes (FUT4, 5, 6, 7, and 9). ${ }^{26}$ The fucosylated glycotypes on serum glycoproteins in milk from 43 healthy mothers were analyzed semiquantitatively by lectin-blotting, where three specific biotinylated lectins were able to recognize and differentiate among the $\alpha 1,2-, \alpha 1,3-$, and $\alpha 1,6$-Fuc linkages. ${ }^{27}$

The type and levels of $\mathrm{N}$-glycans have been previously investigated in mature milk (weeks 12-16) of three mothers. ${ }^{14}$ From the total $52 \mathrm{~N}$-glycans identified, 34 (65\%) N-glycans were fucosylated. ${ }^{14}$ The relative levels of the fucosylated $\mathrm{N}$ glycans covered $>80 \%$ of the total $\mathrm{N}$-glycan content. ${ }^{14}$ However, the type and level of individual $\mathrm{N}$-glycans in milk of the individual mothers have not yet been investigated. ${ }^{14,27}$ More recently, the variation of $\mathrm{N}$-glycans in human milk over lactation has been studied. ${ }^{16}$ In this latter study, milk from 10 mothers was collected and combined per lactation stage (colostrum, 3 days; transition milk, 9 days; and mature milk, 40 days). ${ }^{16}$ It was reported that levels of fucosylated N-glycans

\begin{tabular}{|c|c|c|c|c|c|c|c|}
\hline \multirow[b]{2}{*}{ no. } & \multirow[b]{2}{*}{ mass } & \multicolumn{4}{|c|}{ composition } & \multicolumn{2}{|c|}{ classification: type } \\
\hline & & $\overline{\mathrm{Hex}}$ & HexNAc & Fuc & $\overline{\mathrm{NeuAc}}$ & $\mathrm{I}^{a}$ & $\mathrm{II}^{b}$ \\
\hline N35 & $1827.5^{14,16}$ & 4 & 5 & 1 & 0 & complex & $\mathrm{NF}$ \\
\hline N36 & 1843.5 & 5 & 5 & 0 & 0 & complex & $\mathrm{N}$ \\
\hline N37 & $1874.4^{15}$ & 5 & 3 & 1 & 1 & hybrid & $\mathrm{AF}$ \\
\hline N38 & $1882.5^{14-16}$ & 9 & 2 & 0 & 0 & $\begin{array}{l}\text { high } \\
\text { mannose }\end{array}$ & $\mathrm{N}$ \\
\hline N39 & $1884.5^{16}$ & 4 & 6 & 0 & 0 & complex & $\mathrm{N}$ \\
\hline $\mathrm{N} 40$ & $1931.9^{14-16}$ & 5 & 4 & 0 & 1 & complex & A \\
\hline $\mathrm{N} 41$ & $1932.9^{14,15}$ & 5 & 4 & 2 & 0 & complex & $\mathrm{NF}$ \\
\hline $\mathrm{N} 42$ & $1948.5^{14,15}$ & 6 & 4 & 1 & 0 & complex & NF \\
\hline $\mathrm{N} 43$ & $1972.7^{14}$ & 4 & 5 & 0 & 1 & complex & A \\
\hline N44 & $1989.5^{14,16}$ & 5 & 5 & 1 & 0 & complex & $\mathrm{NF}$ \\
\hline N45 & 2005.6 & 6 & 5 & 0 & 0 & complex & $\mathrm{N}$ \\
\hline $\mathrm{N} 46$ & $2014.5^{15}$ & 3 & 6 & 2 & 0 & complex & $\mathrm{NF}$ \\
\hline N47 & 2036.6 & 6 & 3 & 1 & 1 & complex & $\mathrm{AF}$ \\
\hline $\mathrm{N} 48$ & 2060.9 & 4 & 4 & 0 & 2 & complex & A \\
\hline N49 & $2077.5^{14-16}$ & 5 & 4 & 1 & 1 & complex & $\mathrm{AF}$ \\
\hline N50 & $2078.6^{14,15}$ & 5 & 4 & 3 & 0 & complex & $\mathrm{NF}$ \\
\hline N51 & $2094.6^{15}$ & 6 & 4 & 2 & 0 & complex & $\mathrm{NF}$ \\
\hline N52 & $2118.7^{14,15}$ & 4 & 5 & 1 & 1 & complex & $\mathrm{AF}$ \\
\hline N53 & $2134.7^{14}$ & 5 & 5 & 0 & 1 & complex & A \\
\hline N54 & 2135.5 & 5 & 5 & 2 & 0 & complex & NF \\
\hline N55 & $2151.6^{14}$ & 6 & 5 & 1 & 0 & complex & $\mathrm{NF}$ \\
\hline N56 & 2167.6 & 7 & 5 & 0 & 0 & complex & $\mathrm{N}$ \\
\hline N57 & $2176.7^{15}$ & 4 & 6 & 2 & 0 & complex & $\mathrm{NF}$ \\
\hline N58 & $2224.6^{14}$ & 5 & 4 & 4 & 0 & complex & $\mathrm{NF}$ \\
\hline N59 & $2240.7^{15}$ & 6 & 4 & 3 & 0 & complex & $\mathrm{NF}$ \\
\hline N60 & $2297.7^{14,16}$ & 6 & 5 & 2 & 0 & complex & $\mathrm{NF}$ \\
\hline N61 & 2313.6 & 7 & 5 & 1 & 0 & complex & $\mathrm{NF}$ \\
\hline N62 & 2354.8 & 6 & 6 & 1 & 0 & complex & $\mathrm{NF}$ \\
\hline N63 & 2370.8 & 5 & 4 & 5 & 0 & complex & NF \\
\hline N64 & $2443.8^{14,16}$ & 6 & 5 & 3 & 0 & complex & $\mathrm{NF}$ \\
\hline N65 & $2459.8^{14}$ & 7 & 5 & 2 & 0 & hybrid & $\mathrm{NF}$ \\
\hline N66 & $2500.6^{15}$ & 6 & 6 & 2 & 0 & complex & $\mathrm{NF}$ \\
\hline
\end{tabular}

${ }^{a}$ Type I classification: complex, hybrid, high-mannose, and other $\mathrm{N}$ glycans. ${ }^{b}$ Type II classification: N, neutral nonfucosylated N-glycans; $\mathrm{NF}$, neutral fucosylated N-glycans; A, acidic nonfucosylated $\mathrm{N}$ glycans; AF, acidic fucosylated N-glycans. dropped from ca. $61 \%$ in colostrum to $37 \%$ in transition milk and then remained constant in mature milk. ${ }^{16}$ This current study set out to investigate the individual differences in type and levels of $\mathrm{N}$-glycans in milk between mothers.

The main objective was to profile and compare $\mathrm{N}$-glycans in colostrum (week 1) and mature milk (week 4) of seven Chinese mothers differing in secretor status using matrixassisted laser desorption ionization time of flight mass spectrometry (MALDI-TOF-MS).

\section{MATERIAL AND METHODS}

Chemicals. Ammonium bicarbonate, sodium chloride, acetonitrile $(\mathrm{MeCN})$, trifluoroacetic acid (TFA), and ethanol (EtOH) were purchased from Biosolve B.V. (Valkenswaard, The Netherlands). Water was filtered using the Milli- $Q$ water purification system of Merck Millipore (Molsheim, France). Sodium dodecyl sulfate (SDS), 2-mercaptoethanol (2-BME), 2,5-dihydroxybenzoic acid (DHB), fetuin originated from fetal bovine serum, and branched octylphenoxy poly(ethoxy)ethanol (IGEPAL CA-630) were provided by SigmaAldrich (St. Louis). A mixture of maltodextrins was obtained from Avebe (Veendam, The Netherlands). The complex N-glycans $\mathrm{NA}_{2}$ 
(No. 24) and $\mathrm{NA}_{2} \mathrm{~F}$ (No. 33) and the high-mannose structures Man6 (No. 11) and Man8 (No. 27) (Table 1) were provided by Ludger (Oxfordshire, U.K.). Peptidyl N-glycosidase F (PNGase F) was bought from Asparia Glycomics (San Sebastian, Spain).

Human Milk Collection and the Mother's SeLe Status. Milk samples from seven healthy mothers who delivered term (38-42 weeks) infants were assessed in week 1 (colostrum) and week 4 (mature milk) postpartum. Human milk collection was approved by the Chinese Ethics Committee of Registering Clinical Trials (ChiECRCT-20150017). Written informed consent was obtained from all mothers. The milk was categorized based on the mother's SeLe group, using liquid chromatography-mass spectrometry (LCMS) quantification of four secretor-status-specific HMOs, 2'fucosyllactose, lacto- $\mathrm{N}$-fucopentaose I, lacto- $\mathrm{N}$-difucosylhexaose I, and lacto$N$-tetraose, as described previously $(\mathrm{M} 1=$ mother $26, \mathrm{M} 2=20, \mathrm{M} 3=$ 22, M4 $=25, \mathrm{M} 5=23, \mathrm{M} 6=21, \mathrm{M} 7=24) .{ }^{28}$ Mothers 1 and 4 belong to the $\mathrm{Se}^{-} \mathrm{Le}^{+}$group, whereas mothers $2,3,5,6$, and 7 were assigned to the $\mathrm{Se}^{+} \mathrm{Le}^{+}$group. Milk samples from $\mathrm{Se}^{+} \mathrm{Le}^{-}$and $\mathrm{Se}^{-} \mathrm{Le}^{-}$mothers are not represented in this study.

Isolation of Human Milk Serum Proteins. The lipid layer was removed from the human milk samples $(7 \mathrm{~mL})$ after centrifugation (10 min, $1500 \mathrm{~g}, 4^{\circ} \mathrm{C}$ ), and the obtained skim milk was transferred to ultracentrifuge tubes. ${ }^{11}$ After ultracentrifugation (90 min, 100.000g, 4 ${ }^{\circ} \mathrm{C}$ ), the top layer represented the remaining milk fat still present, the middle layer was milk serum (consisting of serum proteins and free oligosaccharides), and the bottom layer consisted of micellar casein. ${ }^{11}$ The glycoproteins from the milk fat globule membrane, which represent $1-2 \%$ of the total protein content, were not taken into consideration in this study. ${ }^{6}$ Although these latter glycoproteins have small contributions in nutritional value, they have been reported to play an important role in various cellular processes and defense mechanisms in the newborn. ${ }^{6}$ Serum proteins were separated from the HMOs via EtOH precipitation, ${ }^{15}$ with modifications. Milk serum (3 $\mathrm{mL}$ ) was diluted twice, and then absolute $\mathrm{EtOH}$ was added until a relative concentration of $67 \% \mathrm{EtOH}$ was reached. After $67 \% \mathrm{EtOH}$ precipitation $\left(60 \mathrm{~min}, 4^{\circ} \mathrm{C}\right.$ ) and centrifugation $(15 \mathrm{~min}, 1500 \mathrm{~g}, 4$ ${ }^{\circ} \mathrm{C}$ ), the supernatant containing HMOs was discarded. The pellet containing serum proteins was redissolved in $0.5 \mathrm{~mL}$ of water, and $\mathrm{EtOH}$ precipitation was repeated three times. Finally, serum proteins in the pellet were redissolved in $0.5 \mathrm{~mL}$ of $200 \mathrm{mM}$ ammonium bicarbonate $(\mathrm{pH} 8)$ using alternately a vortex and an ultrasonic bath at room temperature. The final experiments (after method optimization and validation) were done in duplicate.

Release and Purification of N-Glycans from Serum Proteins. Methods were based upon previously described methods, ${ }^{14,15,29-32}$ with modifications. Briefly, $1 \mu \mathrm{L}$ of $1 \mathrm{M}$ SDS in water and $10 \mu \mathrm{L}$ of 2 $\mathrm{BME}$ were combined with $100 \mu \mathrm{L}$ of the solution containing the human milk serum proteins and kept for $10 \mathrm{~min}$ at $95^{\circ} \mathrm{C}$. Optimization of the denaturation steps was done with fetuin. Fetuin is folded by these disulfide bonds, and SDS was not strong enough to break down the covalent bridges. ${ }^{29}$ A sulfhydryl reducing reagent, like 2-BME, is essential to release $\mathrm{N}$-glycans.

After cooling down to $37{ }^{\circ} \mathrm{C}$, solutions with the denatured serum proteins were diluted with $50 \mu \mathrm{L}$ of $100 \mathrm{mM}$ ammonium bicarbonate and mixed with $50 \mu \mathrm{L}$ of $4 \%(\mathrm{v} / \mathrm{v})$ IGEPAL CA-630. A wide range of concentrations (range: $50-200 \mathrm{mM}$ ) has been used before starting incubation with PNGase $\mathrm{F}^{15,29,32}$ and here the final concentration of the samples was $100 \mathrm{mM}$. To protect the PNGase $\mathrm{F}$ from denaturation by SDS, IGEPAL CA-630 as a nonionic detergent was added, although the mechanism behind this protection effect is still unknown. ${ }^{29}$ For the complete release of N-glycans from human milk serum proteins, the mixture was incubated with PNGase F $(24 \mathrm{~h}, 37$ $\left.{ }^{\circ} \mathrm{C}\right), 6 \mu \mathrm{L}$ of enzyme at $t=0$ followed by $4 \mu \mathrm{L}$ of enzyme after $16 \mathrm{~h}$. Redigestion of the deglycosylated proteins with PNGase F after $16 \mathrm{~h}$ provided sufficient reaction time and guaranteed the action of the enzyme, resulting in more released $\mathrm{N}$-glycans in numbers compared to other incubation times.

After incubation, the mixtures containing $\mathrm{N}$-glycans and deglycosylated proteins were mixed with absolute EtOH until a relative concentration of $67 \% \mathrm{EtOH}$ was reached and stored for 60 $\min$ at $4{ }^{\circ} \mathrm{C}$. After centrifugation $\left(15 \mathrm{~min}, 1500 g, 4{ }^{\circ} \mathrm{C}\right)$, the supernatant was dried under a stream of air overnight, and the $\mathrm{N}$ glycans thereafter reconstituted with $0.5 \mathrm{~mL}$ of water.

The N-glycans in solution were further purified by solid-phase extraction using a graphitized carbon column cartridge (bed weight: $150 \mathrm{mg}$; tube size: $4 \mathrm{~mL}$; Alltech, Deerfield). ${ }^{14}$ Removing excess salts, denatured proteins, and other reagents by $\mathrm{EtOH}$ precipitation is necessary before definitive characterization of the $\mathrm{N}$-glycans. Besides sediment by cold EtOH, solid-phase extraction was used for purification of the $\mathrm{N}$-glycans. The recovery of $\mathrm{N}$-glycans from graphitized cartridges was checked using a set of standards. The cartridge was prepared with $2 \mathrm{~mL}$ of water, followed by $2 \mathrm{~mL}$ of $80 \%$ $\mathrm{MeCN}$ containing $0.1 \%$ TFA. The cartridge was conditioned with 2 $\mathrm{mL}$ of water before loading $0.5 \mathrm{~mL}$ of the sample with $\mathrm{N}$-glycans. The $\mathrm{N}$-glycans on the cartridge were eluted with $0.5 \mathrm{~mL}$ of $10 \% \mathrm{MeCN}$, $0.5 \mathrm{~mL}$ of $20 \% \mathrm{MeCN}$, and $0.5 \mathrm{~mL}$ of $40 \% \mathrm{MeCN}$ in water containing $0.05 \%$ TFA. The N-glycan mixtures were dried under a stream of air overnight. After reconstitution in $20 \mu \mathrm{L}$ of water, the solution containing N-glycans was ready for MALDI-TOF-MS analysis.

Analysis of N-Glycans by MALDI-TOF-MS. Analysis of Nglycans by MALDI-TOF-MS was done, as described previously. ${ }^{33}$ MALDI-TOF mass spectra were recorded using an UltraFlextreme workstation controlled by FlexControl 3.3 software (Bruker Daltonics, Bremen, Germany) equipped with a Smartbeam II laser of $355 \mathrm{~nm}$ and operated in both positive and negative modes. Since the same glycans were detected in both negative and positive modes and no differences were found in the relative response between neutral and acidic glycans, spectra obtained in the positive mode were described in the result section, due to better reproducibility. Spectra were collected from 1500 laser shots with an energy level of 30\%. The spectrometer was calibrated using a mixture of maltodextrins in a mass range of 500-3000 Da. The complex N-glycans $\mathrm{NA}_{2}$ (No. 24) and $\mathrm{NA}_{2} \mathrm{~F}$ (No. 33) and the high-mannose structures Man6 (No. 11) and Man8 (No. 27) in solution were used as N-glycan standards. The numbers behind the four standards correspond with the numbers in Table 1 . The matrix solution was prepared by mixing $25 \mathrm{mg}$ of DHB in $1 \mathrm{~mL}$ of $50 \% \mathrm{MeCN} / 50 \%$ water (containing $1 \mathrm{mM}$ sodium chloride) and subsequent centrifugation $\left(5 \mathrm{~min}, 1500 \mathrm{~g}, 4^{\circ} \mathrm{C}\right.$ ). For each sample containing $\mathrm{N}$-glycans, $1 \mu \mathrm{L}$ was added directly on the ground steel MS target plate (Bruker Daltonics), followed by $1 \mu \mathrm{L}$ of the matrix solution, and dried under a stream of air. DHB always crystallized as needlelike crystals along the boundary of the MS target plate, which result in heterogeneous sample distribution. Conditions of improved crystallization were checked in this study, and various matrix solutions have been tested.

Data analysis of N-glycans was performed with Flex Analysis 3.3 (Bruker Daltonics). Peak intensities of the individual N-glycans were used if the peak height of the $\mathrm{N}$-glycans was 3 times higher than background noise. For data normalization, the MALDI-TOF-MS peak intensities for each $\mathrm{N}$-glycan were transformed into percentages, by relating the peak intensity of each $\mathrm{N}$-glycan in a sample to the total signal intensity of all of the identified $\mathrm{N}$-glycans within a sample. The data of the individual $\mathrm{N}$-glycans for two biological replicates were averaged. We used pure N-glycans to standardize the method, and technical replicates measured with MALDI-TOF-MS were precise, accurate, and reproducible. The structures of the $\mathrm{N}$-glycans were assigned via the online database GlyTouCan using their molecular mass. ${ }^{34}$ No distinction could be made between molecular isomers. For each structure, just one possible isomer was selected for visualization. Interpretation of the $\mathrm{N}$-glycan profiles in human milk was facilitated by principal component analysis (PCA) and heatmaps using R (Lucent Technologies, New York). The relative levels of the individual $\mathrm{N}$-glycans in milk per mother and per lactation stage were used. Information about the mother's SeLe status was omitted from the data set during statistical analysis. The data for the PCA analysis was mean-centered and Pareto-scaled prior to analysis. Before plotting a heatmap and dendrogram, Spearman's rank correlations were compared, $p$-values were corrected with the BenjaminiHochberg false discovery rate (FDR) method, and then represented 
in a heatmap with a dendrogram. For statistical analysis, an FDR adjusted $p$-value of $<0.05$ was considered significant.

\section{RESULTS AND DISCUSSION}

Analysis of N-Glycans by MALDI-TOF-MS. To analyze all N-glycans present in milk, colostrum (week 1) and mature milk (week 4) of seven Chinese mothers were analyzed. The removal of $\mathrm{HMOs}$ with the right concentration of $\mathrm{EtOH}$ was the most crucial step to get the optimal signal-to-noise ratio by MALDI-TOF-MS and to identify more individual N-glycans. An example of a MALDI-TOF mass spectrum for colostrum (week 1) from Chinese mother 4 can be found in Figure 1, highlighting the 15 most abundant $\mathrm{N}$-glycans.

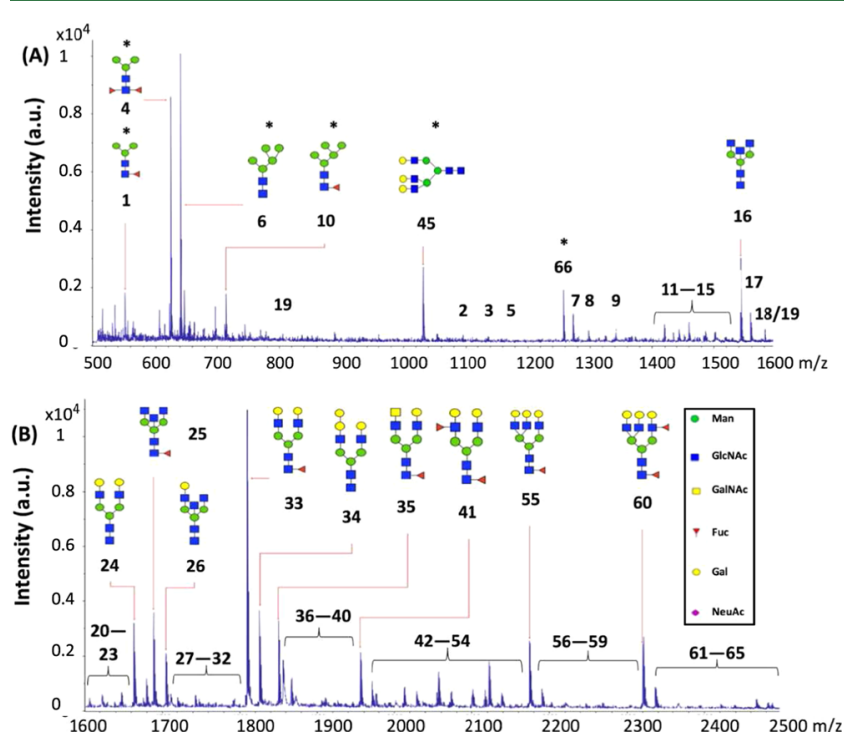

Figure 1. MALDI-TOF mass spectrum, highlighting the 15 most abundant $\mathrm{N}$-glycans in colostrum (week 1) of Chinese mother 4. The numbers of the putative $\mathrm{N}$-glycans correspond with the numbers in Table 1 and Figure 2. (A) Spectrum with $\mathrm{m} / z$ ranging from 500 to 1600 and (B) $\mathrm{m} / z$ ranging from 1600 to 2500 . Just one possible isomer was selected for visualization. The $\mathrm{N}$-glycans highlighted with an asterisk were doubly charged.

The structures of the different putative $\mathrm{N}$-glycans numbered in Figure 1 can be found in Figure 2, which were assigned via the online database GlyTouCan. ${ }^{34}$ The top $15 \mathrm{~N}$-glycans have a pentasaccharide as a common core, consisting of three Man and two GlcNAc residues (Figure 1). More than half of the top $15 \mathrm{~N}$-glycans contained a Fuc residue, and none of them contained a NeuAc residue (Figure 1). No distinction could be made between the different molecular isomers by MALDITOF-MS. The molecular mass of the different N-glycans numbered in Figure 1 can be found in Table 1. However, not all of the 66 different putative $\mathrm{N}$-glycans, as summarized in Table 1, were found in colostrum of each individual Chinese mother.

Overview of Identified N-Glycans in Colostrum (Week 1) and Mature Milk (Week 4) of Seven Chinese Mothers. An overview of all of the identified putative Nglycans in human milk can be found in Figure 2 and Table 1, combining the data obtained by MALDI-TOF-MS of the seven mothers from two different lactation periods. In total, 66 different $\mathrm{N}$-glycan compositions were detected in human milk over time by MALDI-TOF-MS (Table 1), a higher number than previously reported in the literature. ${ }^{14-16}$ Of these $66 \mathrm{~N}$ - glycans, 42 (64\%) were found in all human milk samples: 48 $(73 \%)$ and $43(65 \%)$ unique structures were detected in colostrum and mature milk, respectively (Table S1). Among these $66 \mathrm{~N}$-glycans, $42(64 \%)$ structures can be classified as complex $\mathrm{N}$-glycans, $5(7 \%)$ as high mannose, and $12(18 \%)$ as hybrid (Table 1 , classification system type $\mathrm{I}^{15}$ ), while seven structures $(11 \%)$ could not be classified in one of these three groups and are referred to in Table 1 as "other". The other Nglycans 10 and 17 both have a Fuc residue (Figure 2), excluding them as high-mannose $\mathrm{N}$-glycans. The other $\mathrm{N}$ glycans 1, 2, 4, and 5 did not have 5-9 Man residues (Figure 2). High-mannose N-glycans merely consist of Man building blocks. The other N-glycan 3 lacks either a Fuc or Gal residue (Figure 2) to be classified as hybrid N-glycan and does not have two or three GlcNAc residues like the complex N-glycans (Figure 2).

Another classification system has been introduced to group the different types of N-glycans. ${ }^{14}$ Using this classification system, $11(17 \%)$ and $55(83 \%)$ structures can be grouped as acidic and neutral $\mathrm{N}$-glycans, respectively, and $37(56 \%)$ as fucosylated (Table 1 , classification system type $\mathrm{II}^{14}$ ). The relative occurrence of fucosylated $\mathrm{N}$-glycans in human milk has been mentioned in several studies. ${ }^{4-16}$ Two earlier studies found that the numbers of fucosylated $\mathrm{N}$-glycans ranged between 65 and $75 \% \cdot{ }^{14,15} \mathrm{~A}$ more recent paper, which used a larger sample size (10 mothers and three time points), found that $16(55 \%)$ of the $29 \mathrm{~N}$-glycans found were fucosylated. ${ }^{16}$ Based on the structural features of the $\mathrm{N}$-glycans, as mentioned in the literature, ${ }^{26,35}$ the fucosylated N-glycans in Figure 2 with a single Fuc residue are probably $\alpha 1$,6-linked by FUT 8 during biosynthesis to the GlcNAc residue at the reducing end. The $\mathrm{N}$-glycans containing more than one Fuc residue (Figure 2) might be formed due to the presence of other fucosyltransferases. Multiple (>50) N-glycans from different blood and tissue glycoproteins have been structurally characterized, containing $\alpha 1,2-, \alpha 1,3-$, and $\alpha 1,6$-linked Fuc linkages. ${ }^{35}$ The extra Fuc residues in the $\mathrm{N}$-glycans of these blood and tissue glycoproteins were $\alpha 1,2$ - and $\alpha 1,3$-linked to a Gal residue and a peripheral GlcNAc residue, respectively. ${ }^{35}$ It has also been found that fucosylation of N-glycans is modified by FUT2, ${ }^{24}$ which decorates the Fuc residues by $\alpha 1,2$-linkages. ${ }^{24}$ These fucose-containing $\mathrm{N}$-glycans might also be important for the infant's healthy development, as has been reported for fucosylated HMOs. ${ }^{36}$

Untargeted Statistics with the Relative Levels of Individual N-Glycans in Milk of Seven Chinese Mothers Over Lactation. The averaged levels of the individual Nglycans per mother and per lactation stage can be found in Table S1. Separation of the different clusters coincides with the type of secretor status and lactation time as indicated in Figure 3.

Mothers 1 and 4 can be assigned to the $\mathrm{Se}^{-} \mathrm{Le}^{+}$group, whereas mothers $2,3,5,6$, and 7 belong to the $\mathrm{Se}^{+} \mathrm{Le}^{+}$group. Based on the PCA plot, three different groups could be observed (I-III). For the first time, a clear difference can be observed with respect to milk of two $\mathrm{Se}^{-} \mathrm{Le}^{+}$mothers (I) and five $\mathrm{Se}^{+} \mathrm{Le}^{+}$mothers (II and III), based on the levels of the individual $\mathrm{N}$-glycans. Although the sample size for $\mathrm{Se}^{-} \mathrm{Le}^{+}$ mothers $(N=2)$ is too small for strong conclusions, the distinction between secretor status of the mothers can be clearly seen for both colostrum and mature milk. It can also be observed that milk of the $\mathrm{Se}^{+} \mathrm{Le}^{+}$mothers was strongly grouped per lactation stage (II and III). A similar trend could be 


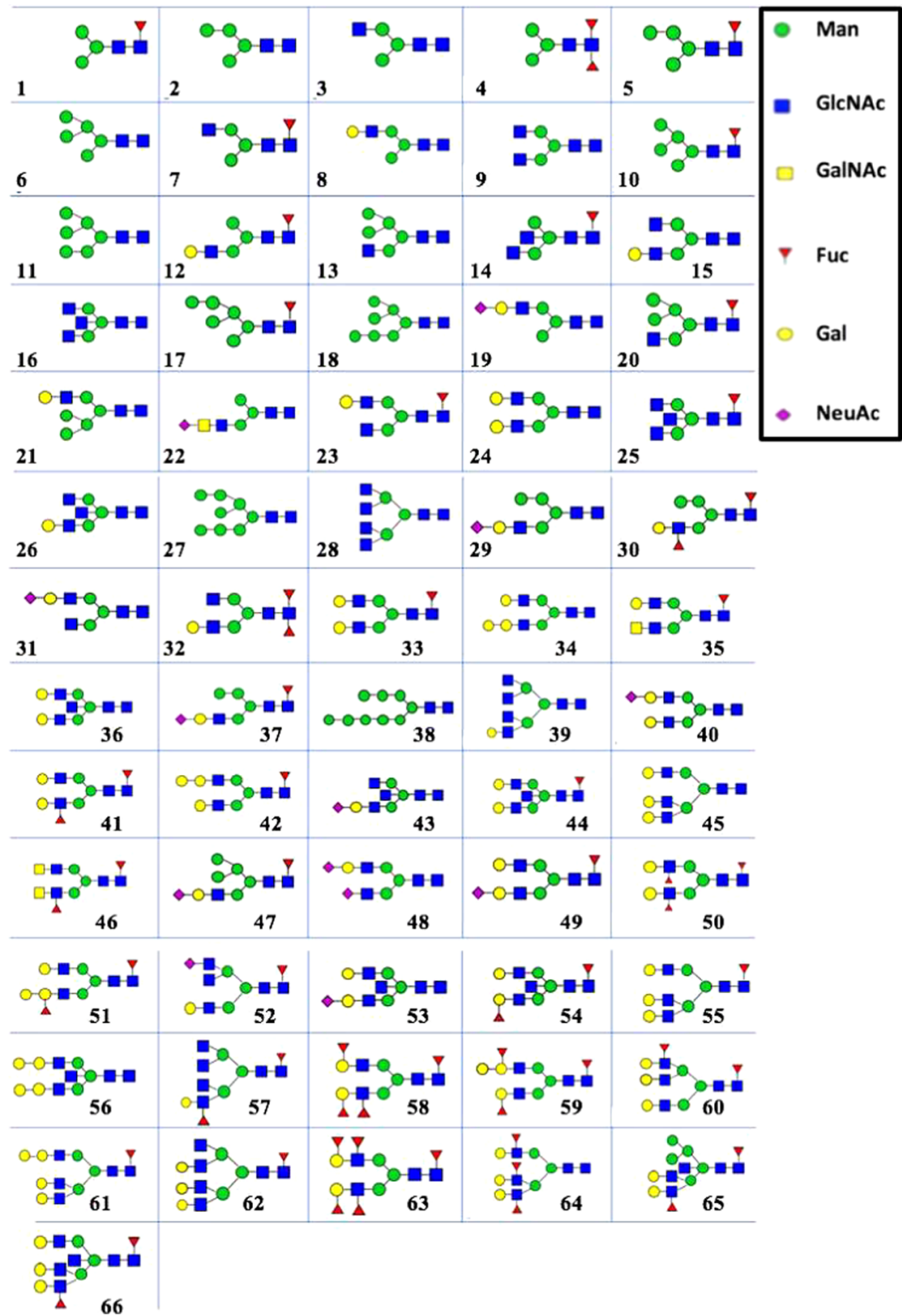

Figure 2. Overview of 66 putative N-glycans identified in colostrum (week 1) and mature milk (week 4) of seven Chinese mothers using MALDITOF-MS. Numbers indicate the N-glycans displayed in Table 1 . The structures of the identified N-glycans were assigned via the online GlyTouCan database based on their molecular mass. ${ }^{34}$ Just one possible isomer is shown.

observed for the two $\mathrm{Se}^{-} \mathrm{Le}^{+}$mothers; however, a larger sample size is needed for confirmation.

Individual N-Glycans in Milk of $\mathrm{Se}^{+} \mathrm{Le}^{+}$and $\mathrm{Se}^{-} \mathrm{Le}^{+}$ Mothers Over Lactation Grouped on Classification Systems I and II. The levels of the 66 different N-glycan compositions were grouped, according to classification systems I (Figure S1) and II (Figure 4) per mother and lactation stage. Based on classification system I (high mannose, complex, hybrid, and other N-glycans), the relative levels of the total high-mannose and total other $\mathrm{N}$-glycans decreased over lactation for the two $\mathrm{Se}^{-} \mathrm{Le}^{+}$mothers, whereas the relative levels of the total complex $\mathrm{N}$-glycans increased over time (Figure S1). The relative levels of the total hybrid N-glycans remained constant over lactation (Figure S1). The group containing the complex $\mathrm{N}$-glycans covered $>65 \%$ of the total $\mathrm{N}$-glycan content, for all seven mothers (Figure S1). It has been reported before that complex $\mathrm{N}$-glycans individually are highly abundant in human milk and the most dominant type of N-glycans present in mature milk among mothers. ${ }^{14}$

As mentioned above, classification system II considered all of the different structural features of the N-glycans. The levels of the total neutral fucosylated N-glycans in milk from five $\mathrm{Se}^{+} \mathrm{Le}^{+}$mothers slightly decreased over lactation, while the total levels of acidic $\mathrm{N}$-glycans remained constant, and the total levels of neutral nonfucosylated $\mathrm{N}$-glycans increased (Figure 4). This pattern could not be observed for the milk from the two $\mathrm{Se}^{-} \mathrm{Le}^{+}$mothers. The profiles of the three $\mathrm{N}$-glycan groups stayed constant over lactation for the two $\mathrm{Se}^{-} \mathrm{Le}^{+}$mothers (Figure 4). Despite the different patterns, the relative levels of the total neutral (sum of nonfucosylated and fucosylated) Nglycans end up being the same for both genetic groups (Figure 4). The relative levels of total neutral N-glycans covered $>90 \%$ of the total $\mathrm{N}$-glycan as present in the mass spectrum, for all seven mothers (Figure 4). 


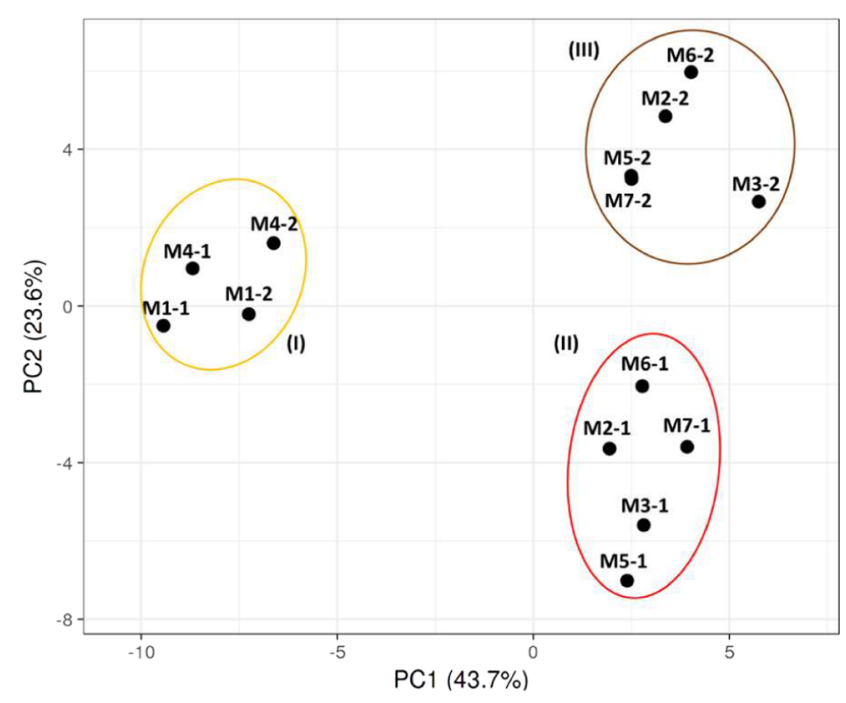

Figure 3. PCA plot of the Chinese human milk N-glycome over lactation, using the relative level of each single $\mathrm{N}$-glycan per mother and per lactation stage. Mothers 1 and 4 were assigned to the $\mathrm{Se}^{-} \mathrm{Le}^{+}$ group, whereas mothers $2,3,5,6$, and 7 were grouped in the $\mathrm{Se}^{+} \mathrm{Le}^{+}$ group. The numbers after the hyphen per mother indicate colostrum (1) and mature milk (2).

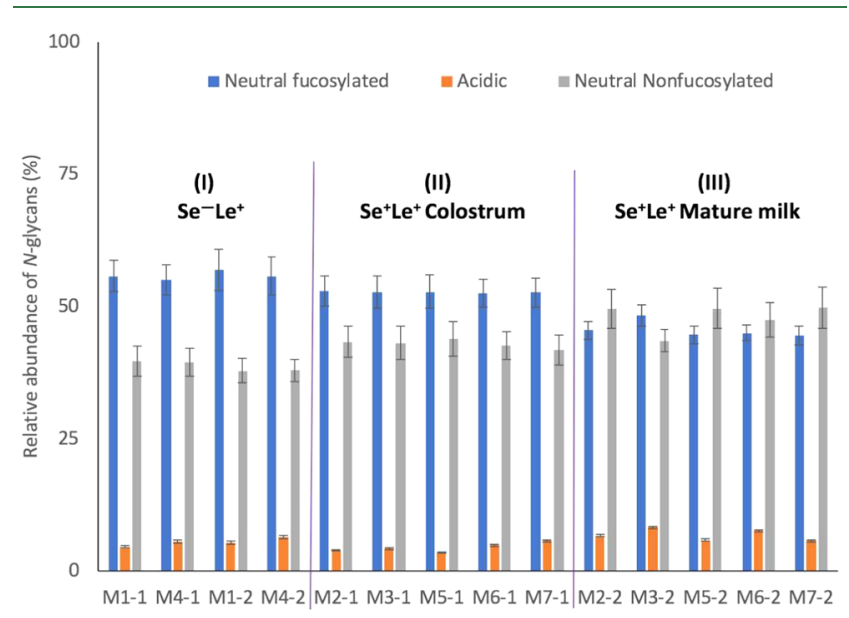

Figure 4. Total acidic and neutral (nonfucosylated and fucosylated) $\mathrm{N}$-glycan content in milk of seven mothers from two different lactation periods. The acidic (nonfucosylated and fucosylated) $\mathrm{N}$ glycans were grouped together. Mothers 1 and 4 were assigned to the $\mathrm{Se}^{-} \mathrm{Le}^{+}$group, whereas mothers $2,3,5,6$, and 7 belong to the $\mathrm{Se}^{+} \mathrm{Le}^{+}$ group. The numbers after the hyphen per mother indicate colostrum (1) and mature milk (2). Roman numerals (I-III) refer to the groups in the PCA plot in Figure 3.

The patterns for the total acidic and total neutral N-glycan contents of human milk proteins over lactation (Figure 4) did not completely match with the literature. ${ }^{16}$ It has been reported by others that the levels of fucosylated N-glycans decreased from ca. $61 \%$ in colostrum (3 days) to $37 \%$ in transition milk ( 9 days) and then remained constant in mature milk (40 days). ${ }^{16}$ This large drop could not be observed here for neutral fucosylated N-glycans over time (Figure 4). It was also reported that the levels of the nonfucosylated N-glycans increased over time and the levels of acidic N-glycans in milk proteins over time ranged from 5 to $12 \%$, with a little increase over lactation. ${ }^{16}$ In this current study, the relative amounts of the total acidic $\mathrm{N}$-glycans ranged between 3 and $8 \%$ in milk of seven mothers over time (Figure 4). However, none of the acidic $\mathrm{N}$-glycans belong here to the most abundant $\mathrm{N}$-glycans (Table S2). Two other studies showed a completely different pattern for the acidic N-glycans in mature milk. ${ }^{14,15}$ By abundance, 47 and $57 \%$ of the $\mathrm{N}$-glycans were sialylated. ${ }^{14,15}$

Twenty-seven $\mathrm{N}$-glycans were not found in our study (Table S3), as compared to the literature, ${ }^{14-16}$ including 13 acidic $\mathrm{N}$ glycans (Table S3). It seems unlikely that these acidic Nglycans in Tables 1 and S3 belong to the most abundant $\mathrm{N}$ glycans. Some of the highly acidic N-glycans (e.g., 1915.7, 2881.1) were only found once in the literature (Table S3), while other structures (e.g., 40, 49) were found in low quantities by us (Table S1) and others. ${ }^{15,16}$ In addition, a recent study investigated the core fucosylation patterns of serum proteins in milk of 56 Chinese mothers. In this latter study, acidic $\mathrm{N}$-glycans were also not highly abundant in human milk. The type and level of individual N-glycans in milk of the individual mothers were not investigated, as the study evaluated the role of FUT8 with respect to the formation of a healthy micriobiota. ${ }^{25}$

Individual N-Glycans in Colostrum (Week 1) and Mature Milk (Week 4) of Seven Chinese Mothers. Besides the PCA plot, also a heatmap was generated. The differences in individual $\mathrm{N}$-glycans in colostrum and mature milk of the Chinese mothers can be investigated using a heatmap, showing variation in both the type and levels of specific individual $\mathrm{N}$-glycans among mothers and over time (Figure 5). For example, the level of the neutral fucosylated $\mathrm{N}$ glycan 25 for Chinese mother 2 was higher in colostrum than in mature milk (Figure 5). The level of the neutral fucosylated $\mathrm{N}$-glycan 33 was higher in both colostrum and mature milk from Chinese mother 4 in comparison to Chinese mother 2 (Figure 5).

Although the heatmap (Figure 5) provided insights into the Chinese human milk N-glycome over lactation, it is quite hard to observe accurately the differences in type and levels of individual $\mathrm{N}$-glycans between the individual mothers and over lactation. Therefore, the profiles of the individual N-glycans over time can be found in Figures 6 and 7 for milk of Chinese mother $2\left(\mathrm{Se}^{+} \mathrm{Le}^{+}\right.$status $)$and Chinese mother $4\left(\mathrm{Se}^{-} \mathrm{Le}^{+}\right.$ status), respectively.

Levels of the Individual N-Glycans in Colostrum and Mature Milk of Chinese Mother 2 with the $\mathrm{Se}^{+} \mathrm{Le}^{+}$ Status. It can be seen in Figure 6 that neutral nonfucosylated $\mathrm{N}$-glycan 16 and fucosylated N-glycan 25 are both highly abundant in colostrum (13.0\%) of Chinese mother 2. Other highly abundant neutral $\mathrm{N}$-glycans in colostrum of Chinese mother 2 are structures 35, 33, 26, 11, 41, 6, 24, 36, 23, 44, 34, 15 , and 50 , ordered from most to least abundant (Figure 6).

The levels of the neutral nonfucosylated N-glycans 16 and 34 increased $(14.4 \rightarrow 17.3 \%$ and $1.6 \rightarrow 2.3 \%)$ over time, respectively (Figure 6). The levels of the neutral fucosylated $\mathrm{N}$-glycans 25,35 , and 41 decreased $(12.3 \rightarrow 7.9 \%, 9.3 \rightarrow 5.0 \%$, and $3.2 \rightarrow 2.2 \%$ ) over lactation, respectively (Figure 6 ). The levels of the neutral nonfucosylated N-glycan 36 also decreased $(2.6 \rightarrow 1.8 \%)$ from colostrum to mature milk (Figure 6$)$. The neutral fucosylated $\mathrm{N}$-glycans 4,5 , and 10 were completely absent in milk of Chinese mother 2 (Figure 6). The neutral fucosylated $\mathrm{N}$-glycans 7 and 46, the nonfucosylated $\mathrm{N}$-glycans 38 and 39, and acidic nonfucosylated $\mathrm{N}$-glycan 40 were only present in colostrum, while the acidic nonfucosylated $\mathrm{N}$-glycan 19 and neutral fucosylated N-glycan 29 were only present in mature milk (Figures 6 and 2). 


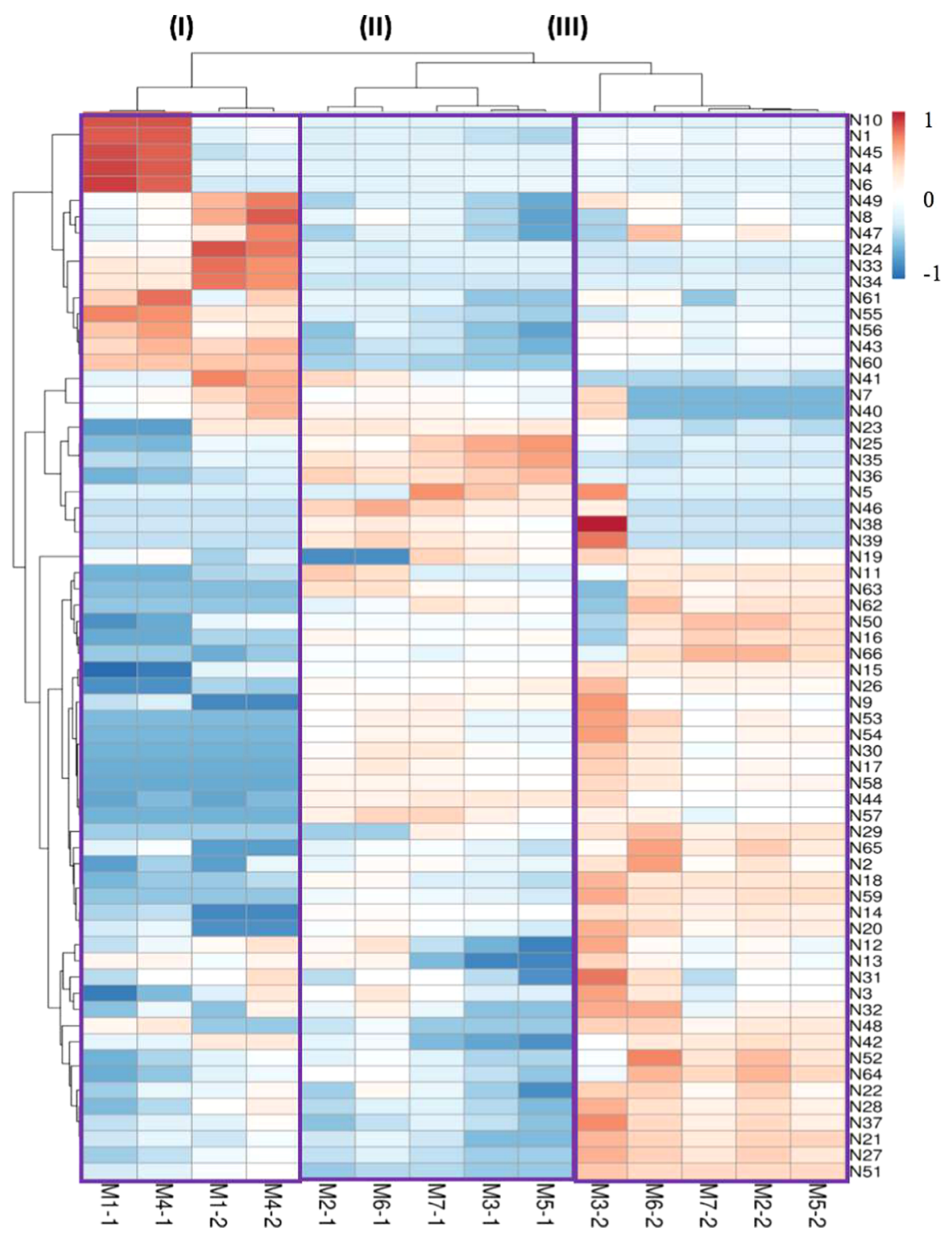

Figure 5. Heatmap of N-glycans in colostrum and mature milk per mother, using the relative abundancies of each single N-glycan. The levels of individual $\mathrm{N}$-glycans are represented as different colors. The colors blue and red represent the lowest and highest values of the N-glycans, respectively. Mothers 1 and 4 were assigned to the $\mathrm{Se}^{-} \mathrm{Le}^{+}$group, whereas mothers 2, 3, 5, 6, and 7 were grouped in the $\mathrm{Se}^{+} \mathrm{Le}^{+}$group. The numbers after the hyphen per mother indicate colostrum (1) and mature milk (2). Roman numerals (I-III) refer to the groups in the PCA plot in Figure 3.

Levels of the Individual N-Glycans in Colostrum and Mature Milk of Chinese Mother 4 with the $\mathrm{Se}^{-} \mathrm{Le}^{+}$ Status. It can be seen in Figure 7 that the neutral fucosylated $\mathrm{N}$-glycan 33 is highly abundant in colostrum (13.2\%) of Chinese mother 4 . The other highly abundant $\mathrm{N}$-glycans in colostrum of Chinese mother 4 are $6,4,34,25,35,24,16,45$, $55,60,26,41,1$, and 10 , ordered from most to least abundant (Figure 7). The majority of the top 15 structures can be categorized as neutral fucosylated $\mathrm{N}$-glycans (Figure 7), despite the fact that this milk belongs to the $\mathrm{Se}^{-} \mathrm{Le}^{+}$group.

The levels of the neutral fucosylated N-glycans 33,25 , and 35 increased $(13.2 \rightarrow 18.7 \%, 4.5 \rightarrow 8.8 \%$, and $4.4 \rightarrow 5.5 \%)$ over lactation, respectively, while the levels of the neutral nonfucosylated $\mathrm{N}$-glycans 6 and 45 decreased $(12.1 \rightarrow 2.5 \%$ and $3.4 \rightarrow 0.6 \%$ ) over time, respectively (Figure 7 ). The levels of the neutral fucosylated N-glycans 4, 55, 1, and 10 decreased $(9.1 \rightarrow 0.5 \%, 3.2 \rightarrow 2.4 \%, 2.1 \rightarrow 0.7 \%$, and $1.9 \rightarrow 0.5 \%)$ from colostrum to mature milk, respectively (Figure 7 ). The levels increased for the nonfucosylated N-glycans $34,24,16,26$, and
$41(4.6 \rightarrow 6.4 \%, 3.9 \rightarrow 6.2 \%, 3.7 \rightarrow 6.3 \%, 2.5 \rightarrow 3.8 \%$, and 2.4 $\rightarrow 3.4 \%$ ) over time, respectively (Figure 7 ).

The neutral fucosylated $\mathrm{N}$-glycans 20 and 65, the neutral fucoyslated $\mathrm{N}$-glycan 9, and the acidic nonfucosylated $\mathrm{N}$ glycan 48 were only present in colostrum (Figure 7). The neutral fucosylated $\mathrm{N}$-glycans 5, 17, 30, 46, 54, 57-59, 62, and 63, the acidic nonfucosylated $\mathrm{N}$-glycans 29 and 53, and the neutral nonfucosylated $\mathrm{N}$-glycans 38 and 39 were completely absent in milk of Chinese mother 4 (Figures 7 and 2).

Comparison of the Individual N-Glycans in Colostrum and Mature Milk of Chinese Mothers 2 and 4 with the $\mathrm{Se}^{+} \mathrm{Le}^{+}$and $\mathrm{Se}^{-} \mathrm{Le}^{+}$Status, Respectively. The neutral fucosylated $\mathrm{N}$-glycan 33 was present in milk of the $\mathrm{Se}^{+} \mathrm{Le}^{+}$and $\mathrm{Se}^{-} \mathrm{Le}^{+}$mother, with higher levels for the $\mathrm{Se}^{-} \mathrm{Le}^{+}$mother in comparison to the $\mathrm{Se}^{+} \mathrm{Le}^{+}$mother (Figures 6 and 7). The levels of the neutral N-glycan 6 were also higher in colostrum for the $\mathrm{Se}^{-} \mathrm{Le}^{+}$mother compared to the $\mathrm{Se}^{+} \mathrm{Le}^{+}$mother. The levels of the neutral fucosylated $\mathrm{N}$-glycans 25 and 35 were higher in colostrum for the $\mathrm{Se}^{+} \mathrm{Le}^{+}$mother in comparison to the $\mathrm{Se}^{-} \mathrm{Le}^{+}$ 


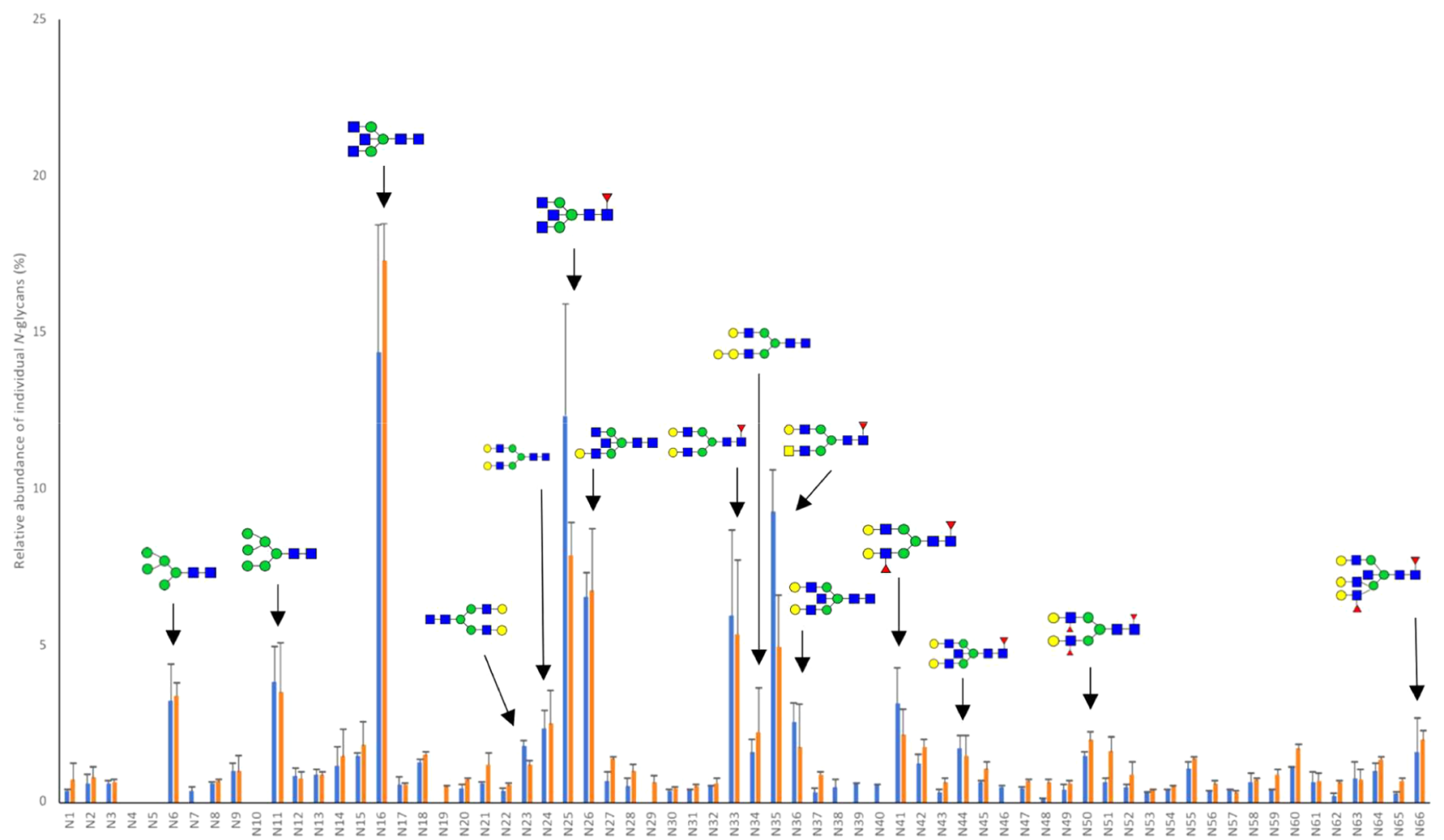

Figure 6. Individual N-glycan profiles in colostrum (blue bars) and mature milk (orange bars) of Chinese mother 2, as measured using MALDITOF-MS. Mother 2 belongs to the $\mathrm{Se}^{+} \mathrm{Le}^{+}$group. Numbers on the $x$-axis indicate the $\mathrm{N}$-glycans displayed in Table 1 . Biological replicates $(N=2)$. The structures displayed highlight the 15 most abundant N-glycans.

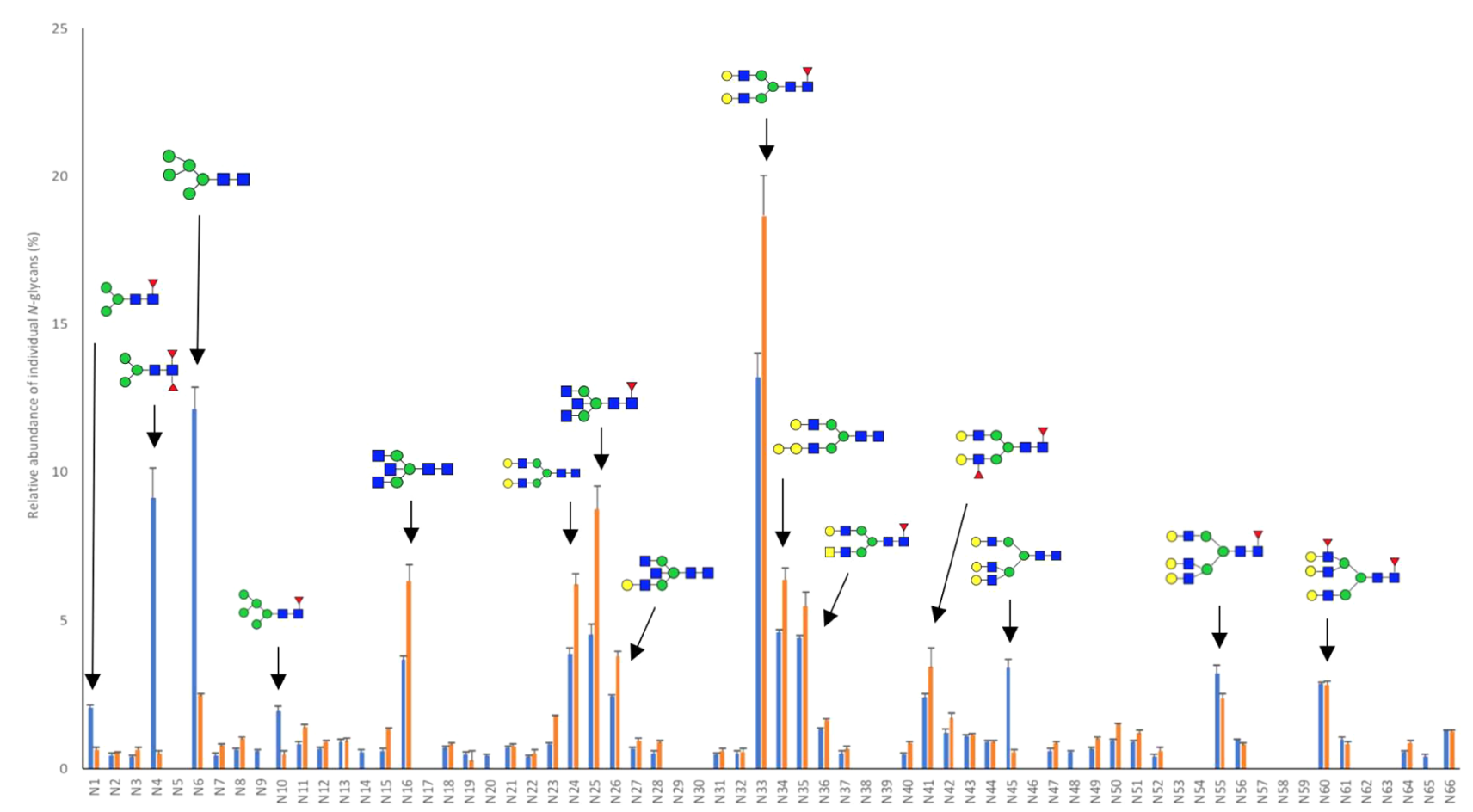

Figure 7. Individual N-glycan profiles in colostrum (blue bars) and mature milk (orange bars) of Chinese mother 4, as measured using MALDITOF-MS. Mother 4 was grouped in the $\mathrm{Se}^{-} \mathrm{Le}^{+}$group. Numbers on the $x$-axis indicate the $\mathrm{N}$-glycans displayed in Table 1 . Biological replicates $(N$ $=2$ ). The structures displayed highlight the 15 most abundant N-glycans.

mother. The levels of the neutral N-glycans 11 and 26 were both higher in colostrum and mature milk for the $\mathrm{Se}^{+} \mathrm{Le}^{+}$ mother in comparison to the $\mathrm{Se}^{-} \mathrm{Le}^{+}$mother. The neutral Nglycan 34 was more dominant in colostrum and mature milk for the $\mathrm{Se}^{-} \mathrm{Le}^{+}$mother in comparison to the $\mathrm{Se}^{+} \mathrm{Le}^{+}$mother. From the total putative $66 \mathrm{~N}$-glycans, the neutral fucosylated $\mathrm{N}$-glycans 4, 5, and 10 were completely absent in the milk from the $\mathrm{Se}^{+} \mathrm{Le}^{+}$mother (Figure 6), while more N-glycans 5, 17, 
$29-30,38-39,46,53,54,57-59$, and $62-63$ were missing in the milk of the $\mathrm{Se}^{-} \mathrm{Le}^{+}$mother of which 10 structures were neutral fucosylated (Figure 7). These missing structures already differentiate between the two different milk types. It might be that structures 54,57-59, and 63, which lack an $\alpha 1,2$-linked Fuc residue, are not present due to the absence of the FUT2 enzyme for the $\mathrm{Se}^{-} \mathrm{Le}^{+}$mother. These latter structures were only present in the milk from the $\mathrm{Se}^{+} \mathrm{Le}^{+}$ mothers (Table S1). Structures 15, 17, and 62 only contain $\alpha 1,6$-linked Fuc residues due to the enzyme FUT8. The $\mathrm{N}$ glycans 30 and 46 were only present in the milk from the $\mathrm{Se}^{+} \mathrm{Le}^{+}$mothers (Table S1), which suggest that these Fuc residues might be $\alpha 1,2$-linked to a Gal residue instead of being $\alpha 1,3$-linked to a peripheral GlcNAc residue (Figure 2). No distinction between molecular isomers could be made by MALDI-TOF-MS.

The levels of the neutral fucosylated N-glycans 25, 33, and 35 decreased from colostrum to mature milk for the $\mathrm{Se}^{+} \mathrm{Le}^{+}$ mother, whereas the neutral $\mathrm{N}$-glycan 16 became more dominant over time. In contrast to the milk from the $\mathrm{Se}^{+} \mathrm{Le}^{+}$ mother, the levels of neutral N-glycans 6 and 45 decreased over time for the $\mathrm{Se}^{-} \mathrm{Le}^{+}$mother, while the levels of the neutral fucosylated N-glycans 25, 33, and 35 increased over time. As a consequence, other neutral fucosylated N-glycans 1, 10, 33, 55, and 60 might explain why the total neutral fucosylated concentration ends up being the same for both genetic groups (Figure 4). The milk of one $\mathrm{Se}^{+} \mathrm{Le}^{+}$mother and one $\mathrm{Se}^{-} \mathrm{Le}^{+}$ mother thus mainly differed based on neutral fucosylated $\mathrm{N}$ glycans. The same top 15 in $\mathrm{N}$-glycans were found in colostrum and mature milk for both $\mathrm{Se}^{-} \mathrm{Le}^{+}$mothers (Table S2). A similar top 15 in N-glycans can be found for all $\mathrm{Se}^{+} \mathrm{Le}^{+}$ mothers over lactation. The profiles of the top $15 \mathrm{~N}$-glycans for the $\mathrm{Se}^{+} \mathrm{Le}^{+}$mothers 3, 5, and 7 have more in common than the $\mathrm{Se}^{+} \mathrm{Le}^{+}$mothers 2 and 6 (Table S2). The patterns (increase/ decrease in levels) of the individual $15 \mathrm{~N}$-glycans behave differently over time for the $\mathrm{Se}^{+} \mathrm{Le}^{+}$mothers 2 and 6 (Table S2) and the $\mathrm{Se}^{+} \mathrm{Le}^{+}$mothers 3, 5, and 7. The 15 most abundant $\mathrm{N}$-glycans covered in levels $>72$ and $>65 \%$ of the total $\mathrm{N}$ glycan content in colostrum and mature milk, respectively (Table S2). In contrast to the most abundant serum proteins ${ }^{11}$ and $\mathrm{HMOs}^{28}$ in human milk, a much larger variety in type and levels can be observed for the top $15 \mathrm{~N}$-glycans among mothers and over lactation. This indicates that lesser abundant $\mathrm{N}$-glycans should deserve the same attention as the relative highly abundant $\mathrm{N}$-glycans. Overall, $\mathrm{N}$-glycans share several building blocks with HMOs although the latter do not have Man and GalNAc residues. In addition, most N-glycan and HMO structures are fucosylated. Based on this study, it can be concluded that fucosylation of $\mathrm{N}$-glycans was associated with the mother's secretor status.

This study aimed to fill a gap in the literature by investigating the $\mathrm{N}$-glycan profiles in milk of seven mothers over lactation individually. For this purpose, an accurate and reproducible method was needed. The procedure to remove HMOs was efficient, addition of 2-BME improved denaturation of serum proteins, and the incubation time and amount of the PNGase F were optimized. After method optimization and validation, a larger set of human milk samples was used. Acidic $\mathrm{N}$-glycans do not belong to the 15 most abundant N-glycans, as mainly neutral fucosylated and nonfucosylated $\mathrm{N}$-glycans can be found in colostrum and mature milk, for all seven mothers. The difference between secretor status was mainly based on the neutral fucosylated $\mathrm{N}$-glycans.

\section{ASSOCIATED CONTENT}

Supporting Information

The Supporting Information is available free of charge at https://pubs.acs.org/doi/10.1021/acs.jafc.0c02161.

Data of individual N-glycan levels in Chinese human milk per mother during lactation (Table S1); the 15 most abundant $\mathrm{N}$-glycans (Table S2); comparison of $\mathrm{N}$ glycans between different studies in the literature (Table S3); N-glycans grouped according to classification system I (Figure S1) (PDF)

\section{AUTHOR INFORMATION}

\section{Corresponding Author}

Henk A. Schols - Laboratory of Food Chemistry, Wageningen University \& Research, 6708 WG Wageningen, The Netherlands; 10 orcid.org/0000-0002-5712-1554; Phone: +31 317 482239; Email: henk.schols@wur.nl

\section{Authors}

Mohèb Elwakiel - Laboratory of Food Chemistry and Food Quality and Design, Wageningen University \& Research, 6708 WG Wageningen, The Netherlands

Edwin J. Bakx - Laboratory of Food Chemistry, Wageningen University \& Research, 6708 WG Wageningen, The Netherlands

Ignatius M. Szeto - Inner Mongolia Yili Industrial Group Co., Ltd., 010110 Hohhot, China

Yitong Li - Inner Mongolia Yili Industrial Group Co., Ltd., 010110 Hohhot, China

Kasper A. Hettinga - Food Quality and Design, Wageningen University \& Research, 6708 WG Wageningen, The Netherlands

Complete contact information is available at: https://pubs.acs.org/10.1021/acs.jafc.0c02161

\section{Funding}

Funding for this project was received from Yili Industrial Group Company.

\section{Notes}

The authors declare no competing financial interest.

\section{ACKNOWLEDGMENTS}

The authors want to thank Melliana Jonathan (Food Chemistry, Wageningen University \& Research) for the fruitful discussions on the isolation, extraction, and characterization of N-glycans.

\section{ABBREVIATIONS}

EtOH, ethanol; Fuc, fucose; FUT, fucosyltransferases; Gal, galactose; GalNAc, $N$-acetylgalactosamine; GlcNAc, $N$-acetylglucosamine; HMOs, human milk oligosaccharides; IGEPAL CA-630, branched octylphenoxy poly(ethoxy)ethanol; Le, Lewis status; MALDI-TOF-MS, matrix-assisted laser desorption ionization time of flight mass spectrometry; Man, mannose; MeCN, acetonitrile; NeuAc, sialic acid; PCA, principal component analysis; PNGase F, peptidyl $N$ glycosidase F; Se, secretor status; SDS, sodium dodecyl sulfate; TFA, trifluoroacetic acid; 2-BME, 2-mercaptoethanol; DHB, 2,5-dihydroxybenzoic acid 


\section{REFERENCES}

(1) Kunz, C.; Rodriguez-Palmero, M.; Koletzko, B.; Jensen, R. Nutritional and biochemical properties of human milk, part I: General aspects, proteins, and carbohydrates. Clin. Perinatol. 1999, 26, 307333.

(2) Labbok, M. H.; Clark, D.; Goldman, A. S. Breastfeeding: Maintaining an irreplaceable immunological resource. Nat. Rev. Immunol. 2004, 4, 565-572.

(3) Ballard, O.; Morrow, A. L. Human milk composition: Nutrients and bioactive factors. Pediatr. Clin. North Am. 2013, 60, 49-74.

(4) Bode, L. Recent advances on structure, metabolism, and function of human milk oligosaccharides. J. Nutr. 2006, 136, 2127-2130.

(5) De Leoz, M. L. A.; Wu, S.; Strum, J. S.; Niñonuevo, M. R.; Gaerlan, S. C.; Mirmiran, M.; German, J. B.; Mills, D. A.; Lebrilla, C. B.; Underwood, M. A. A quantitative and comprehensive method to analyse human milk oligosaccharide structures in the urine and faeces of infants. Anal. Bioanal. Chem. 2013, 405, 4089-4105.

(6) Hettinga, K. A.; Van Valenberg, H.; De Vries, S.; Boeren, S.; Van Hooijdonk, T.; Van Arendonk, J.; Vervoort, J. The host defense proteome of human and bovine milk. PLoS One 2011, 6, No. e19433.

(7) Froehlich, J. W.; Dodds, E. D.; Barboza, M.; McJimpsey, E. L.; Seipert, R. R.; Francis, J.; An, H. J.; Freeman, S.; German, J. B.; Lebrilla, C. B. Glycoprotein expression in human milk during lactation. J. Agric. Food Chem. 2010, 58, 6440-6448.

(8) Peterson, R.; Cheah, W. Y.; Grinyer, J.; Packer, N. Glycoconjugates in human milk: Protecting infants from disease. Glycobiology 2013, 23, 1425-1438.

(9) Karav, S.; Le Parc, A.; de Moura Bell, J. M. L. N.; Frese, S. A.; Kirmiz, N.; Block, D. A.; Barile, D.; Mills, D. E. Oligosaccharides released from milk glycoproteins are selective growth substrates for infant-associated bifidobacteria. Appl. Environ. Microbiol. 2016, 82, $3622-3630$.

(10) Kirmiz, N.; Robinson, R. C.; Shah, I. M.; Barile, D.; Mills, D. A. Milk glycans and their interaction with the infant-gut microbiota. Annu. Rev. Food Sci. Technol. 2018, 9, 429-450.

(11) Elwakiel, M.; Boeren, S.; Hageman, J. A.; Szeto, I. M.; Schols, H. A.; Hettinga, K. A. Variability of serum proteins in Chinese and Dutch human milk during lactation. Nutrients 2018, 11, No. 499.

(12) Lönnerdal, B. Bioactive proteins in human milk: Health, nutrition, and implications for infant formulas. J. Pediatr. 2016, 173, S4-S9.

(13) Picariello, G.; Ferranti, P.; Mamone, G.; Roepstorff, P.; Addeo, F. Identification of $\mathrm{N}$-linked glycoproteins in human milk by hydrophilic interaction liquid chromatography and mass spectrometry. Proteomics 2008, 8, 3833-3847.

(14) Dallas, D. C.; Martin, W. F.; Strum, J. S.; Zivkovic, A. M.; Smilowitz, J. T.; Underwood, M. A.; Affolter, M.; Lebrilla, C. B.; German, J. B. N-linked glycan profiling of mature human milk by high performance microfluidic chip liquid chromatography time of flight tandem mass spectrometry. J. Agric. Food Chem. 2011, 59, 42554263.

(15) Nwosu, C. C.; Aldredge, D. L.; Lee, H.; Lerno, L. A.; Zivkovic, A. M.; German, J. B.; Lebrilla, C. B. Comparison of the human and bovine milk $\mathrm{N}$-glycome via high-performance microfluidic chip liquid chromatography and tandem mass spectrometry. J. Proteome Res. 2012, 11, 2912-2924.

(16) Lu, Y.; Liu, J.; Jia, Y.; Yang, Y.; Chen, Q.; Sun, L.; Song, S.; Huang, L.; Wang, Z. Mass spectrometry analysis of changes in human milk N/O-glycopatterns at different lactation stages. J. Agric. Food Chem. 2019, 67, 10702-10712.

(17) Van Leeuwen, S. S.; Schoemaker, R. J. W.; Timmer, C. J. A. M.; Kamerling, J. P.; Dijkhuizen, L. $N$ - and O-glycosylation of a commercial bovine whey protein product. J. Agric. Food Chem. 2012, 60, 12553-12564.

(18) Takimori, S.; Shimaoka, H.; Furukawa, J.-I.; Yamashita, T.; Amano, M.; Fujitani, N.; Takegawa, Y.; Hammarstrom, L.; Kacskovics, I.; Shinohara, Y.; Nishimura, S.-I. Alteration of the Nglycome of bovine milk glycoproteins during early lactation. FEBS $J$. 2011, 278, 3769-3781.
(19) Wang, W.-L.; Wang, L.; Du, Y.-M.; Wu, H.; Yu, X.-B.; Ye, K.-P.; Li, C.-B.; Jung, Y.-S.; Qian, Y.-J.; Voglmeir, J.; Liu, L. Comparison of antipathogenic activities of the human and bovine milk $\mathrm{N}$-glycome: Fucosylation is a key factor. Food Chem. 2017, 235, 167-174.

(20) Landberg, E.; Huang, Y.; Stromgvist, M.; Mechref, Y.; Hansson, L.; Lundblad, A.; Novotny, M. V.; Pahlsson, P. Changes in glycosylation of human bile salt-activated lipase during lactation. Arch. Biochem. Biophys. 2000, 377, 246-254.

(21) Le Parc, A.; Karav, S.; Rouquie, C.; Maga, E. A.; Bunyatratchata, A.; Barile, D. Characterization of recombinant human lactoferrin $\mathrm{N}$-glycans expressed in the milk of transgenic cows. PLoS One 2017, 12, No. e0171477.

(22) Barboza, M.; Pinzon, J.; Wickramasinghe, S.; Froehlich, J. W.; Moeller, I.; Smilowitz, J. T.; Ruhaak, L. R.; Huang, J.; Lönnerdal, B.; German, J. B.; Medrano, J. F.; Weimer, B. C.; Lebrilla, C. B. Glycosylation of human milk lactoferrin exhibits dynamic changes during early lactation enhancing its role in pathogenic bacteria host interactions. Mol. Cell. Proteomics 2012, 11, No. M111.015248.

(23) Royle, L.; Roos, A.; Harvey, D. J.; Wormald, M. R.; Van Gijlswijk-Janssen, D.; Redwan, E.-R. M.; Wilson, I. A.; Daha, M. R.; Dwek, R. A.; Rudd, P. M. Secretory IgA $N$ - and $O$-glycans provide a link between the innate and adaptive immune systems. J. Biol. Chem. 2003, 278, 20140-20153.

(24) Bai, Y.; Tao, J.; Zhou, J.; Fan, Q.; Liu, M.; Hu, Y.; Xu, Y.; Zhang, L.; Yuan, Y.; Li, W.; Ze, X.; Malard, P.; Guo, Z.; Yan, J.; Li, M. Fucosylated human milk oligosaccharides and $\mathrm{N}$-glycans in the milk of Chinese mothers regulate gut microbiome of their breast-fed infants during different lactation stages. mSystems 2018, 3, No. e00206-18.

(25) Li, M.; Bai, Y.; Zhou, J.; Huang, W.; Yan, J.; Tao, J.; Fan, Q.; Liu, Y.; Mei, D.; Yan, Q.; Yuan, J.; Malard, P.; Wang, Z.; Gu, J.; Tanigchi, N.; Li, W. Core fucosulation of maternal milk of $N$-glycans evokes $\mathrm{B}$ cell activation by selectively promoting the L-fucose metabolism of gut Bifidobacterium spp. and Lactobacillus spp. mBio 2019, 10, No. e00128-19.

(26) Holst, S.; Wilding, J. L.; Koprowska, K.; Rombouts, Y.; Wuhrer, M. $N$-glycomic and transcriptomic changes associated with CDX1 mRNA expression in colorectal cancer cell lines. Cells 2019, 8, 273294.

(27) Lis-Kuberka, J.; Kątnik-Prastowska, I.; Berghausen-Mazur, M.; Orczyk-Pawilowicz, M. Lectin-based analysis of fucosylated glycoproteins of human skim milk during 47 days of lactation. Glycoconjugate J. 2015, 32, 665-674.

(28) Elwakiel, M.; Hageman, J. A.; Wang, W.; Szeto, I. M.; van Goudoever, J. B.; Hettinga, K. A.; Schols, H. A. Human milk oligosaccharides in colostrum and mature milk of Chinese mothers: Lewis positive secretor subgroups. J. Agric. Food Chem. 2018, 66, 7036-7043.

(29) Morelle, W.; Michalski, J.-C. Analysis of protein glycosylation by mass spectrometry. Nat. Protoc. 2007, 2, 1585-1602.

(30) Chu, C. S.; Ninonuevo, M. R.; Clowers, B. H.; Perkins, P. D.; An, H. J.; Yin, H.; Killeen, K.; Miyamoto, S.; Grimm, R.; Lebrilla, C. B. Profile of native $N$-linked glycan structures from human serum using high performance liquid chromatography on a microfluidic chip and time-of-flight mass spectrometry. Proteomics 2009, 9, 1939-1951.

(31) Aldredge, D.; An, H. J.; Tang, N.; Waddell, K.; Lebrilla, C. B. Annotation of a serum $\mathrm{N}$-glycan library for rapid identification of structures. J. Proteome Res. 2012, 11, 1958-1968.

(32) Kita, Y.; Miura, Y.; Furukawa, J.-i.; Nakano, M.; Shinohara, Y.; Ohno, M.; Takimoto, A.; Nishimura, S.-I. Quantitave glycomics of human whole serum glycoproteins based on the standardized protocol for liberating $N$-glycans. Mol. Cell. Proteomics 2007, 6, 1437-1445.

(33) Albrecht, S.; van Muiswinkel, G. C. J.; Schols, H. A.; Voragen, A. G. J.; Gruppen, H. Introducing capillary electrophoresis with laserinduced fluorescence detection for the characterization of konjac glucomannan oligosaccharides and their in vitro fermentation behavior. J. Agric. Food Chem. 2009, 57, 3867-3876.

(34) Tiemeyer, M.; Paulson, J.; York, W. S.; Lisacek, F.; Campbell, M. P.; Fijiti, A.; Shinmachi, D.; Yamada, I.; Ranzinger, R.; Aoki- 
Kinoshita, K. F.; et al. GlyTouCan: An accessible glycan structure repository. Glycobiology 2017, 27, 915-919.

(35) Vliegenthart, J. F. G.; Dorland, L.; Van Halbeek, H. High resolution, ${ }^{1} \mathrm{H}$-nuclear magnetic resonance spectroscopy as a tool in the structural analysis of carbohydrates related to glycoproteins. Adv. Carbohydr. Chem. Biochem. 1983, 41, 209-374.

(36) Plaza-Díaz, J.; Fontana, L.; Gil, A. Human milk oligosaccharides and immune system development. Nutrients 2018, 10, No. 1038. 